\title{
Changes in resource allocation among vegetative organs during the clonal growth of Polygonatum humile (Liliaceae) grown in a temperate forest gap
}

\author{
Byeong-Mee Min
}

\begin{abstract}
Background: The aim of this study was to examine the resource allocation among the organs and the leaf morphology of Polygonatum humile. The data were collected from June 2014 to May 2015 in a natural P. humile stand of a temperate forest gap.

Results: The dry weight of new rhizome $\left(R_{0}\right)$ sharply decreased to the time of new shoot sprouting in next year and was constant for $2 \sim 3$ years. However, dry weight of root on $R_{0}$ increased to the end of growth season and, thereafter, decreased slowly along the time elapsed. The correlation coefficients between the rhizome and the leaf sizes were 0.5 for the last year's rhizome $\left(R_{1}\right)$ and 0.6 for $R_{0}$ and were significant at $0.1 \%$ level for $R_{0}$. The increase of one leaf a plant led to increase of the total leaf area, total leaf weight, and stem length. Moreover, the organ sizes' differences between two plants of the one leaf difference were almost significant at 1\% level. In 11-leaf plant, the leaf length/width ratio and specific lea area increased to the second, relative leaf area to the fourth and relative leaf dry weight to the fifth, and thereafter, decreased to the last leaf. The differences in the values of these four parameters between two leaves on a stem were almost significant at $5 \%$ level.

Conclusion: $P$. humile examined showed the close relationships between the last year's rhizome or this year's one and the shoot system (leaf and stem) sizes. The leaf number a shoot greatly influenced specific leaf area. P. humile's leaf might showed diverse morphology with leaf rank on a stem in a forest gap environment.
\end{abstract}

Keywords: Dry weight, Forest gap, Leaf rank, Polygonatum humile, Rhizome, Specific leaf area, Stem

\section{Background}

In temperate deciduous forests, understorey herbaceous plants are more sensitive than those in the open area to sunlight and use diverse strategies for adaptation to their environment. Shade-tolerant plants that can complete life cycle under the canopy slowly grow. However, lightdemanding plants need gaps to grow to full plant size (Legner et al. 2013). Studies for the plant population in gap under the canopy have been performed for many times (Kern et al. 2013). Plants in perennial herb populations in gaps compete with each other for sunlight and for minerals and water in the soil. Energy is needed for understorey herbaceous plant population to sustain their

Correspondence: bmeemin@hanmail.net

Department of Science Education, Dankook University, Yongin 16890, Korea asexual or sexual reproduction. However, photosynthesis is limited by low irradiance, and plant populations should apply proper strategies to ensure reproduction. Asexual reproduction by vegetative growth is generally used by understorey clonal herbaceous plants in temperate forests (Cook 1983, Gao et al. 2012). In these plants, shoot germination consumes root system energy in the early growth season, whereas photosynthetates produced by leaves are transported to the underground part in the late growth season. In these processes, root system biomass of the previous year directly influences the shoot size and, in turn, the latter determines the newly germinated former. However, it is unclear whether leaf area or leaf weight has a greater influence on biomass of the new root system. To accurately estimate biomass of the 
root system, a pertinent indicator is needed (Klinkhamer et al. 1990). Almost all leaves on a woody twig or on a stem of an herbaceous plant develop at the same time in temperate forest (Min 1995, Ishioka et al. 2013). These leaves are exposed to an almost the same microenvironment, so their morphologies or sizes should be similar. However, the leaves on a stem are morphologically and remarkably different from each other (Min 1995). Moreover, it is unclear whether or not this dissimilarity is significant and whether it is caused mainly by genetic factors or by the microenvironments.

Polygonatum humile (Liliaceae) is generally distributed in grasslands or at forest edge in Korea (Choung 1991, Jang 2002), or in grasslands and sand dunes in Japan (Hasegawa and Kudo 2005). This species asexually or sexually reproduces (Lee 2003). In addition, this species flowers in May to June (Lee 2003). Asexual reproduction is accomplished by rhizome (Jang 2002), which grows in soil horizontally. The rhizome forms one main node per year and thus its age can be easily counted. Roots are formed on the rhizome and their number is decreased by their death with time. The shoot appears on the tip of the rhizome and its reported height is $60 \pm 10.1 \mathrm{~cm}$ (Jang et al. 1998), $30 \sim 50 \mathrm{~cm}$ (Choung 1991), 22.4-38.7 cm (Jang 2002), or $15-30 \mathrm{~cm}$ (Lee 2003, Hasegawa and Kudo 2005). The leaves of $P$. humile are oval and have an entire margin (Choung 1991). The reported number of leaves is $5-8$ (Choung 1991) or 13 (Jang et al. 1998). The leaf length and width are $12 \pm 1.6$ and $4.4 \pm 6.7 \mathrm{~cm}$ (Jang et al. 1998) or $4-7$ and $1.5-3 \mathrm{~cm}$ (Lee 2003), respectively. The number of rhizomes newly developed from a shoot is $1-2$ (Choung 1991), 2 (Jang et al. 1998), or 2-4 (Jang 2002), and their length is 1.1-9.2 cm (Choung 1991). These data suggest that $P$. humile has the broad morphological range or is very sensitive to the microenvironment. The properties that $P$. humile is composed of one rhizome-one shoot and its leaf area can be easily estimated (oval and entire) are convenient for studying the relationship between the root and shoot systems and the main factors of leaf variation, without destroying the whole plant. Moreover, energy shifting among roots, rhizome, and shoot (leaf and stem) in the non-flowering $P$. humile is simple and clear, and density is very high in narrow spaces. In Korea, many studies of Polygonatum have been performed in terms of its use in pharmacology or agriculture (Seo et al. 2011), but few ecological studies are available. Moreover, studies for P. humile are scarce and there are only two reports of Choung (1991) and Jang et al. (1998) for Korea.

The aim of this study was to examine the changes in biomass of vegetative parts and the response to the environment in a natural $P$. humile population, the relationship between the number of leaves in a plant, and their properties along the leaf rank on a stem.

\section{Methods}

The location of the study area was at Yeongheung-ri, Yeongwal-eup, Yeongwal-gun, Gangwon province $\left(37^{\circ}\right.$ $11^{\prime} 35.7^{\prime \prime} \mathrm{N}, 128^{\circ} 28^{\prime}$ 04.0"E) (Fig. 1). The study site was $385 \mathrm{~m}$ a.s.l., (slope, $5^{\circ}$; direction, $175^{\circ}$ ). The annual mean air temperature and precipitation in an average year were $10.8{ }^{\circ} \mathrm{C}$ and $1224.1 \mathrm{~mm}$, respectively, and those in 2015 were $12.5^{\circ} \mathrm{C}$ and $676 \mathrm{~mm}$ on Yeongwal Meteorological Station. P. humile grew in a gap created to move a grave to another place (radius, $10 \mathrm{~m}$ ) and was momentarily shaded by trees in the south (Fig. 2a). P. humile's patch was about a $5 \mathrm{~m} \times 6 \mathrm{~m}$ circle. Except for $P$. humile, the herb layer was $5 \%$ in coverage and composed of Aster scaber, Carex lanceolata, Festuca ovina, and Zoysia japonica. The surrounding forest had four layers of vegetation. The tree layer was composed of Pinus densiflora, Quercus mongolica, and Q. dentata and had 90\% coverage. There were $P$. densiflora, Q. serrata, Prunus sargentii, and Euonymus sieboldiana and 40\% coverage in the subtree layer. There were Exochorda serratifolia, Pourthiaea villosa, and Rhododendron mucronulatum in the shrub layer and Carex lanceolata, Leibnizia anandria, and Aster scaber in the herb one. The coverage was $10 \%$ in the former and $1 \%$ in the latter, respectively. Litter layer was $10 \mathrm{~cm}$ deep and A layer of soil was $10 \mathrm{~cm}$ deep. However, the soil of the area that $P$. humila population was distributed had been disturbed by work relocated to grave but had settled by the time of the study. Plant shoots were partly attached to each other and their rhizomes overlapped or were located closely (Fig. 2b, c).

Field survey was carried out six times from June 22, 2014 to May 26, 2015. All plants were dug out together with soil from two $50 \times 50 \mathrm{~cm}$ quadrats, and soil was slowly washed out by running water to prevent roots from breaking. The age of rhizome was up to 4 years. However, the numbers of 4-year and 3-year rhizome samples were very small. Thus, these samples were not analyzed. Only undamaged new rhizomes $\left(R_{0}\right)$ were counted. Rhizomes longer than $6 \mathrm{~cm}$ were used to follow changes in root system biomass during the growth season and to assess the relationship between the root and shoot systems. According to Choung (1991), plants with rhizome longer than $6 \mathrm{~cm}$ did not change their size class in the next year. However, to analyze the total number and length of rhizomes per shoot, all rhizomes were counted. In the lab, plants were divided into the root and shoot systems. Roots were separated according to the age of rhizome and rhizomes were numbered of $R_{0}$ (this year's rhizome), $R_{1}$ (the last year's rhizome), and $R_{2}$ ( 2 years ago rhizome). Leaf ranks on a stem were numbered from the lowest or the first leaf on a stem $\left(\mathrm{L}_{1}\right)$ to the highest (the last leaf on a stem) (Fig. 3). The number of leaves on a stem was from 3 to 13. However, 12-leaf plant (12-L) and 13-leaf plant (13-L) were not sufficiently sampled and were excluded 

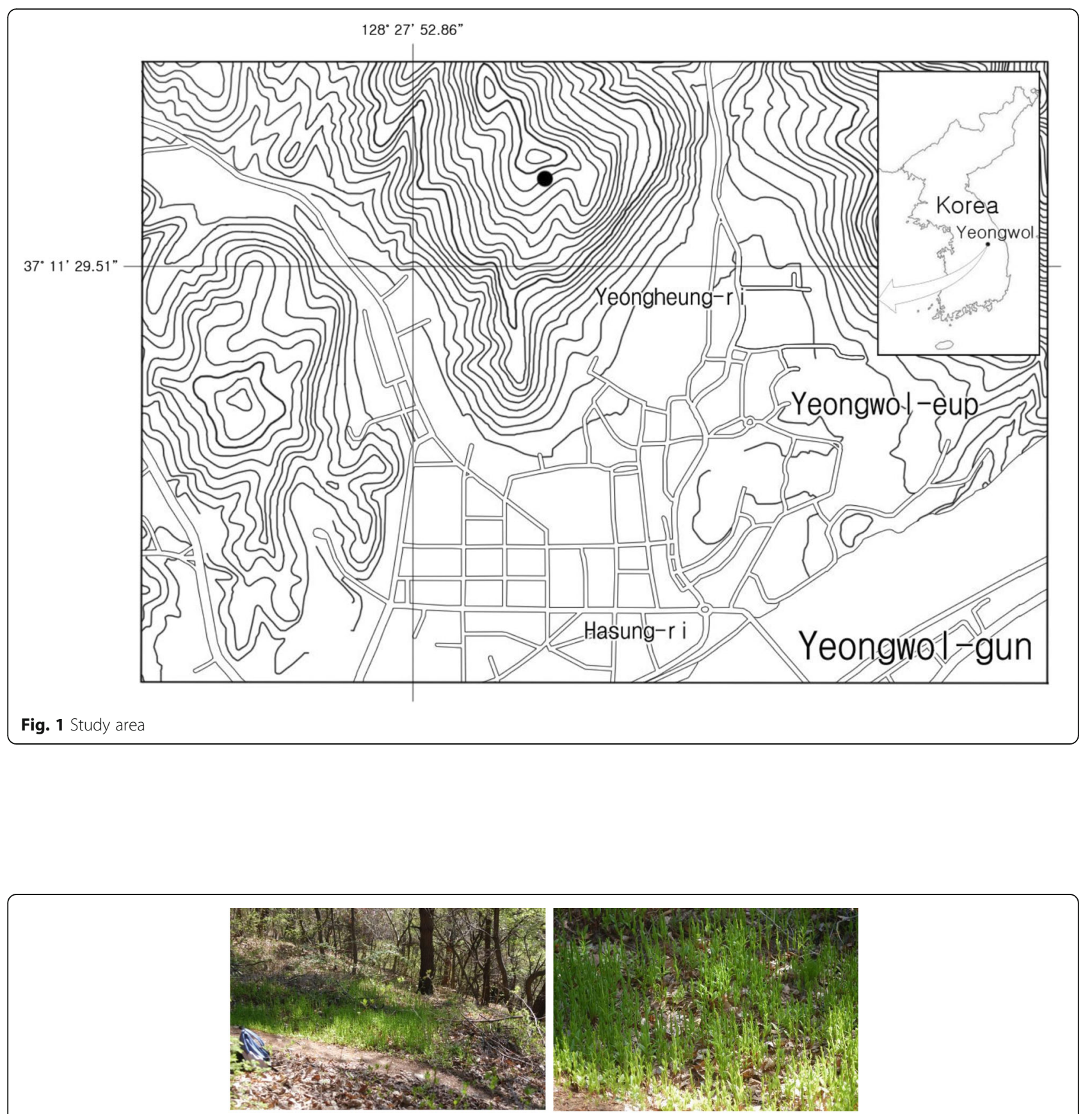

a

b

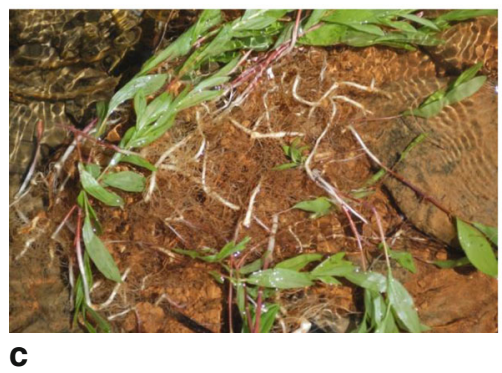

Fig. 2 Natural Polygonatum humile population in study area on April 26, 2015. a Total area, b close-up photographing, c natural form of rhizomes in the soil 


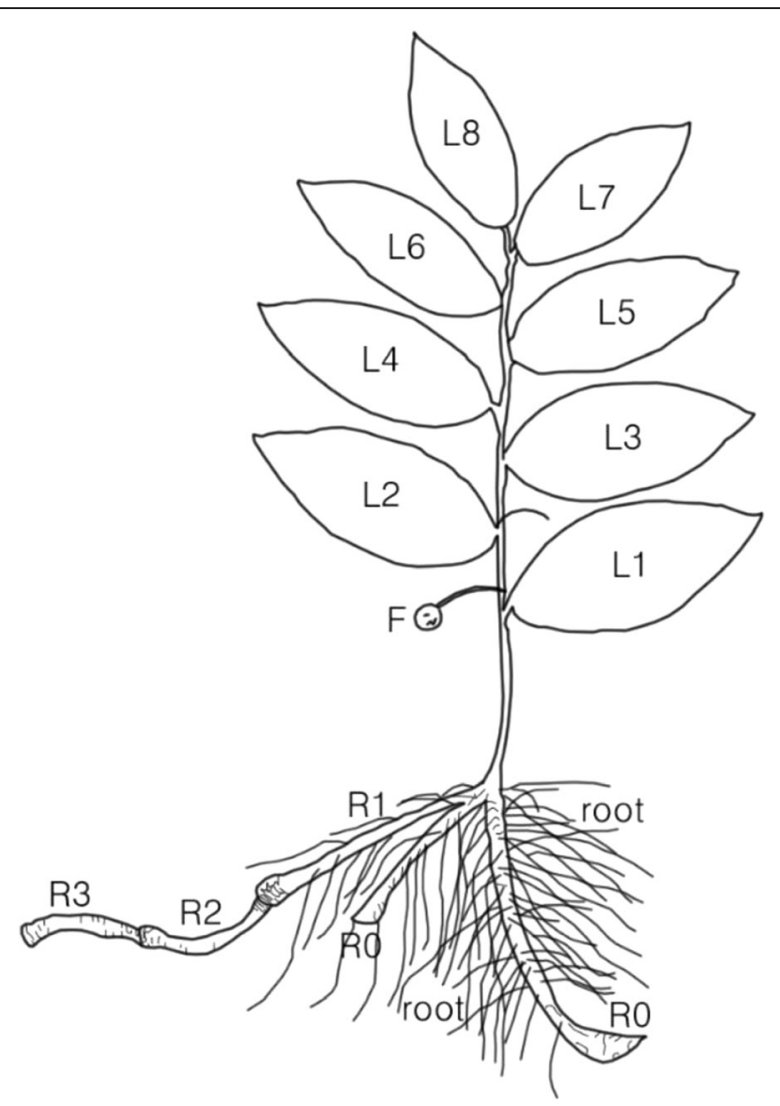

Fig. 3 Schematic diagram of $P$. humile morphology. $R, L$, and $F$ were rhizome, leaf, and fruit, respectively. $R_{0}, R_{1}, R_{2}$ and $R_{3}$ were rhizomes grown in this year (2014), last year (2013), the year before last (2012), and 3 years ago (2011), respectively

from analysis. Length, width and/or area in rhizomes, leaves and stems were measured, followed by oven-drying at $85{ }^{\circ} \mathrm{C}$ for $48 \mathrm{~h}$ and weighing on a Hansung Analytical and Precision Balance, model MARK M (1 mg unit) and model YMJ-C digital leaf area eter $\left(0.0001 \mathrm{~cm}^{2}\right.$ unit). Values of leaf size along the leaf rank were calculated for each leaf relative to those of $\mathrm{L}_{1}$. Significance of the differences was verified by Student $t$-test, and correlation coefficients (CCs) between the two factors were calculated by Pearson's equation $(y=\mathrm{a} x+\mathrm{b})$.

\section{Results}

Relationships between the root and the shoot's systems The number of new rhizomes $\left(R_{0} ;>1 \mathrm{~cm}\right.$ in length) per shoot was 1 , 2, or 3 . Shoots forming three $R_{0} s$ were most represented (Table 1). The largest $R_{0}$ was $25.5 \mathrm{~cm}$ in length, with dry weight of $1262 \mathrm{mg}$. The maximum root dry weight on an $R_{1}$ (the last year's rhizome) or $R_{0}$ was $165 \mathrm{mg}$ and thus was remarkably smaller than that of rhizome. The maximum cumulative length of $R_{0}$ per shoot was $38.5 \mathrm{~cm}$ (Table 2).
Table 1 The number and rate of rhizomes newly germinated from a shoot

\begin{tabular}{lllll}
\hline & \multicolumn{4}{l}{ Number of rhizome } \\
\cline { 2 - 5 } & 1 & 2 & 3 & Total \\
\hline Rate (number) & $16.5 \%(118)$ & $28.1 \%(201)$ & $56.2 \%(395)$ & $100 \%(715)$ \\
\hline
\end{tabular}

$\mathrm{R}_{0}$ biomass was $522.1 \pm 101.2 \mathrm{mg}$ plant $^{-1}$ by June 22 , 2014 and then $775.4 \pm 206.7$ mg.plant ${ }^{-1}$ by August 28, 2014; it was relatively constant before the shoot sprouting in the spring of the next year. However, after shoot sprouting, $R_{1}\left(R_{0}\right.$ in 2014) biomass sharply decreased to $284.6 \pm 88.5 \mathrm{mg}$ plant $^{-1}$ on April 26, 2015. This value was similar to that of $R_{2}\left(260.7 \pm 60.2 \mathrm{mg}\right.$ plant $\left.{ }^{-1}\right)\left(R_{1}\right.$ in 2014) (260.7 \pm 60.2 mg.plant $^{-1}$; Fig. 4). After April 26, 2015, $\mathrm{R}_{1}$ biomass was constant or slightly deceased. The pattern of changes in rhizome thickness (dry weight/rhizome length) was similar to that of rhizome biomass. However, the root's biomass was small from June to August of the first year; it strongly increased before shoot sprouting the next year and continuously decreased thereafter. The root/rhizome dry weight ratio increased until the early growth season of next year and was almost constant thereafter. In 2015, root and shoot systems dry weights were $93.8 \pm 33.9$ and $758.8 \pm 211.1$ mg.plant ${ }^{-1}$ on March 16, 2015 (before shoot sprouting) and $91.0 \pm 28.8$ and $284.6 \pm 88.5$ mg.plant $^{-1}$ on April 26, 2015 (after shoot sprouting), respectively (Table 3). The total dry weight of a plant (root system + shoot system) was smaller than before shoot sprouting (Fig. 5).

In the middle of the growth season (June 22, 2014), the most CC (correlation coefficient) values between the $R\left(R_{0}\right.$ and $R_{1}$ ) and the shoot system size were over 0.4 and significant at $0.1 \%$ level (Table 4 ). Thus, leaf size was a proper indicator for estimating of the total plant size. The largest $C C$ value was 0.753 between dry weight of $R_{0}$ and that of leaves (Fig. 6).

\section{Relationships between the number and the properties of leaves}

$P$. humile had a shoot (or a stem) on a $R_{1}$ and there were from the plants with 3 leaves (3-L plant) to the plants with 11 leaves (11-L plant). For the 11 plant properties-the

Table 2 Maximum values of each property in Polygonatum humile's root system grown per year (a rhizome means section grown for a year)

\begin{tabular}{ll}
\hline Property & Value \\
\hline Length of a rhizome & $25.5 \mathrm{~cm}$ \\
Total length of rhizomes grown from a shoot & $38.5 \mathrm{~cm}$ \\
Dry weight of a rhizome & $1262 \mathrm{mg}$ \\
Total dry weight of rhizomes grown from a shoot & $1540 \mathrm{mg}$ \\
Dry weight of roots on a rhizome & $163 \mathrm{mg}$ \\
Total dry weight of root system grown from a shoot & $1669 \mathrm{mg}$ \\
\hline
\end{tabular}



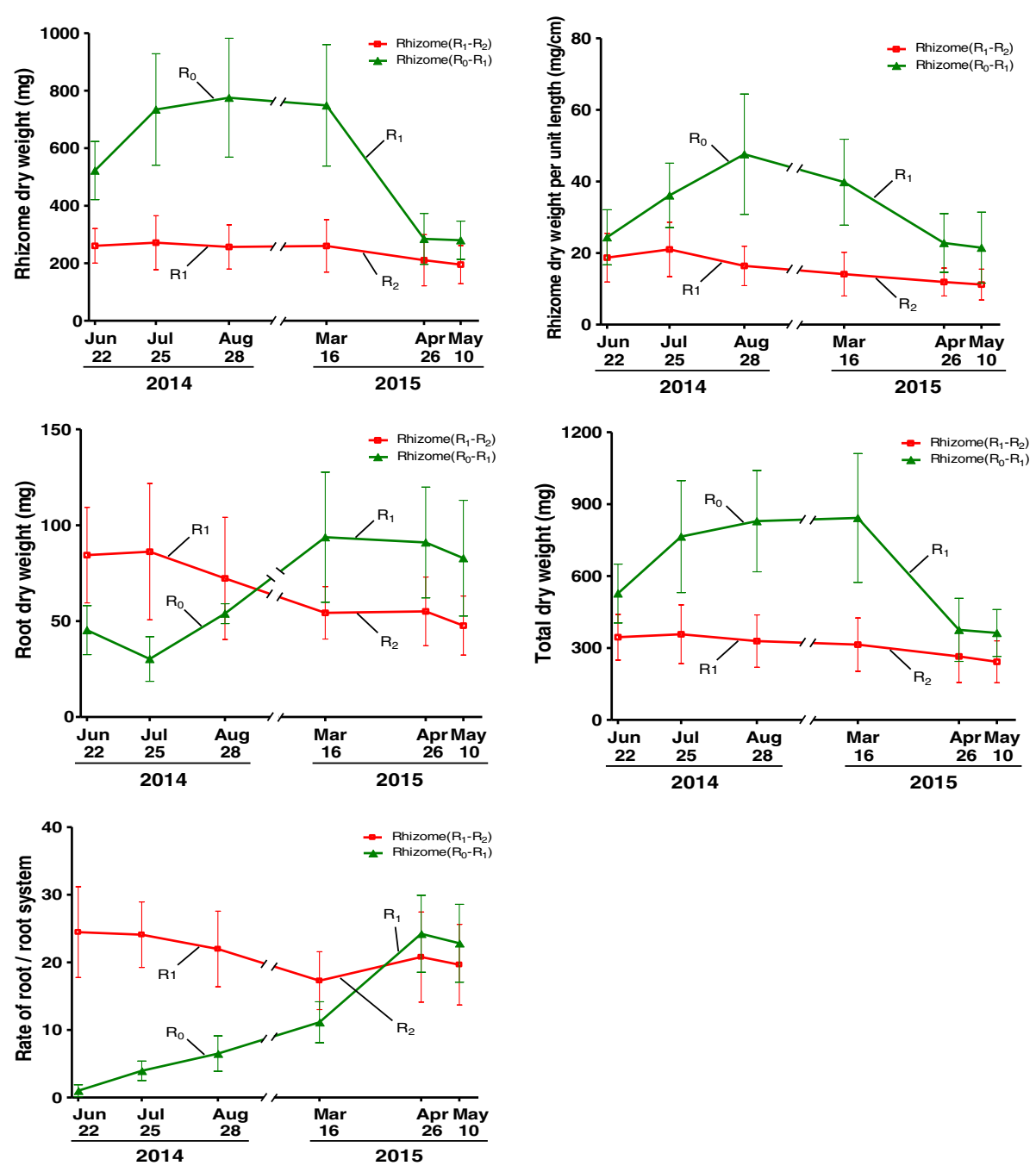

Fig. 4 Changes of the length, the dry weight and thickness of rhizome, root dry weight, total root system (root + rhizome) dry weight and the root/root system dry weight ratio from June 22, 2014 to May 28, 2015. Bars indicate the standard deviation

total leaf area and dry weight per stem, mean leaf area and dry weight per leaf, specific leaf area (SLA), length and dry weight of $R_{0}$ and $R_{1}$, length and dry weight of stemassessed on June 22, 2014, all values increased with the number of leaves except for SLA (Fig. 7). Moreover, an increment of only one leaf resulted in a conspicuous increase in organ property values. Of the total 9 steps from 3-L plant to 11-L plant, the maximum number of steps with the difference in values of plant properties between two leaf type plants significant at $1 \%$ level was 9 for total leaf area per stem. Significant differences at $1 \%$ level were revealed at the 8 steps for stem length and weight and at 7 steps for the total leaf weight per stem and mean leaf area. Thus, the values of these five properties conspicuously increased with the increase in leaf number. Significant differences at $1 \%$ level were observed at 4 steps for $R_{1}$ weight and length and at 3 steps for $R_{0}$ weight, so these three properties were loosely related to leaf number. Of the 11 properties, only SLA decreased with the increase in leaf number. SLA significantly differed at $1 \%$ level at 5 steps, and no significant differences in SLA were found in plants that had $<7$ leaves.

Table 3 Dry weight of each plant organ in Polygonatum humile population (unit; mg)

\begin{tabular}{llllll}
\hline Date & Number & Root system & Leaf & Stem & Shoot system \\
\hline Mar. 16, 2015 & 40 & $852.6 \pm 262.5$ & & & \\
Apr. 26, 2015 & 68 & $375.6 \pm 131.9$ & $286.6 \pm 77.2$ & $96.2 \pm 33.2$ & $382.8 \pm 100.4$ \\
\hline
\end{tabular}

${ }^{\mathrm{a}}$ Before the $P$. humile shoot appearance on the ground

${ }^{\mathrm{b}}$ After the $P$. humile shoot appearance on the ground 


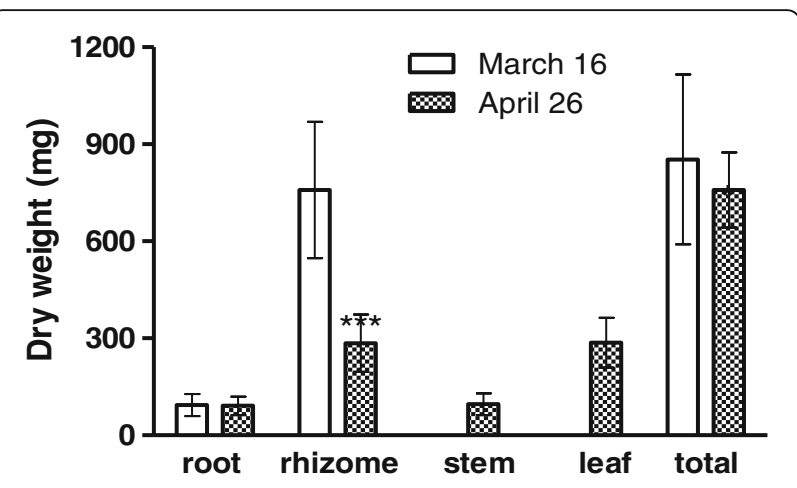

Fig. 5 Dry weight of each organ before (March 16) and after (April 26) the shoot sprouting. Bar indicates standard deviation. ${ }^{* *}$ Significant at $0.1 \%$ level in difference between dry weights of rhizome on March 16 and April 26

\section{Changes in four properties along the leaf rank on a stem and the number of leaves}

The plants used for the leaf rank on a stem analysis were from plants with 4 leaves (4-L plant) to 11 leaves (11-L plant). Of these plants, I considered $11-\mathrm{L}$ plant as the most reliable indicator to show the standard character (Fig. 8). For 11-L, two types of changes in four leaf properties along the leaf rank on a stem from $\mathrm{L}_{1}$ (the first leaf on a stem) to $\mathrm{L}_{11}$ (the 11th leaf on a stem) were observed, one producing a regular curve and the other one an irregular curve. In the former case, the values first increased and then decreased, with the maximum at $\mathrm{L}_{2}$ (the second leaf on a stem) for relative leaf area, $\mathrm{L}_{4}$ (the fourth leaf on a stem) for relative dry weight and $L_{4}$ and $L_{5}$ (the fifth leaf on a stem) for SLA. The curve showed the positive skewness. Of the 55 leaf pairs of the relative leaf area, the differences between the 2 leaves on a stem were significant at $0.1 \%$ in 39 and at $1 \sim 5 \%$ level in 4 . For relative dry weight, the differences were significant at the $0.1 \%$ level in 20 leaf pairs and at $1-5 \%$ level in 18 leaf pairs. However, for SLA the differences almost reached significance at $5 \%$ level in 25 leaf pairs. The latter irregularly fluctuated and was the leaf length/width ratio. Of the 55 leaf pairs, the differences between the 2

Table 4 Correlation coefficients between the rhizome and shoot system in Polygonatum humile population. $R_{1}$ and $R_{0}$ are the last year rhizome and this year one, respectively. Number is samples ( $n$ ). All correlation coefficients are significantly different at an $1 \%$ level

\begin{tabular}{lllll}
\hline Rhizome & \multicolumn{2}{l}{ Shoot system } & Number \\
\cline { 2 - 4 } & $\begin{array}{l}\text { Length } \\
\text { of stem }\end{array}$ & $\begin{array}{l}\text { Weight } \\
\text { of stem }\end{array}$ & $\begin{array}{l}\text { Total weight } \\
\text { of shoot }\end{array}$ & \\
\hline Length of $R_{1}$ & 0.3171 & 0.2583 & 0.2814 & 263 \\
Weight of $R_{1}$ & 0.5420 & 0.5683 & 0.5946 & 263 \\
Length of $R_{0}$ & 0.4947 & 0.4017 & 0.5201 & 51 \\
Weight of $R_{0}$ & 0.5938 & 0.6752 & 0.7143 & 61 \\
\hline
\end{tabular}

leaves on a stem were significant only at the $5 \%$ in four leaf pairs. In plants with leaves $\leq 10$, two types of changes in leaf properties along the leaf rank on a stem were observed. For the leaf length/width ratio, the values along the leaf rank on a shoot showed normal distribution curve in plants with 3-8 leaves and fluctuated in plants with 9 or 10 leaves. However, the differences between the 2 leaves on a stem were not significant for most properties. For the other three properties, the locus of leaf showing the maximum value moved to the $L_{1}$ direction with the decrease in the total number of leaves a stem. In other words, in plants with more leaves, the leaves with the maximum values were located further from $L_{1}$ than in plants with fewer leaves. Moreover, with the increase in the number of leaves per plant, the differences between the 2 leaves on a stem increased and their significance at $0.1 \%$ level increased. For example, for the relative leaf area of a 5 - $\mathrm{L}$ plant, the number of relationships showing significant difference at $0.1 \%$ level was 1 of 12 leaf pairs; however, it was 12 of 28 leaf pairs in a 7 -L plant and 26 of 38 leaf pairs in a 9-L plant. However, the numbers of leaf pair in which the difference was significant at $0.1 \%$ level were dissimilar to each other among the three properties for the same leaf plants. In the plants with a small number of leaves (4 to 7 leaves), leaf properties changed along the leaf rank on a stem; however, the patterns of these changes were irregular and most of the difference was not significant.

\section{Discussion}

In northern temperate deciduous forest, understorey perennial herbs receive little sunlight because they are shaded by the canopy (Embrog 1998, Whingham 2004). Thus, these plants should respond and acclimate to a lowlight environment. In this environment, gap provides a good refuge for these plants (Kem et al. 2013). In this study, a $P$. humile population showed a morphological diversity for sunlight. First, $P$. humile's rhizome grew up to $25.5 \mathrm{~cm}$ in length. This is in contrast to the data of Choung (1991), who reported that the maximal growth of $P$. humile's rhizome was $9.2 \mathrm{~cm}$ under nearly full sunlight. Thus, the growth of $P$. humile rhizome was longer at this study site than in other study. This strategy might be the means to avoid shade and is in clonal plants (Gao et al. 2012). Moreover, the number of $P$. humile's rhizomes generated on a shoot was 1-3 in most plants, rather than $2-4$ by Jang (2002). In general, foraging of rhizome is observed in environment with nutrient resource heterogeneity (Dong and Alaten 1999). Second, the shoots of $P$. humile sprouted in spring using root system energy. Thus, root system biomass decreased in accordance with shoot sprouting. In this study, root system dry weight decreased to $44 \%$ (375.6 $\pm 131.9 \mathrm{mg} \cdot$ plant $^{-1}$ on April 26, 2015 and $852.6 \pm 262.5 \mathrm{mg} \cdot$ plant $^{-1}$ on March 16, 2015) after the 

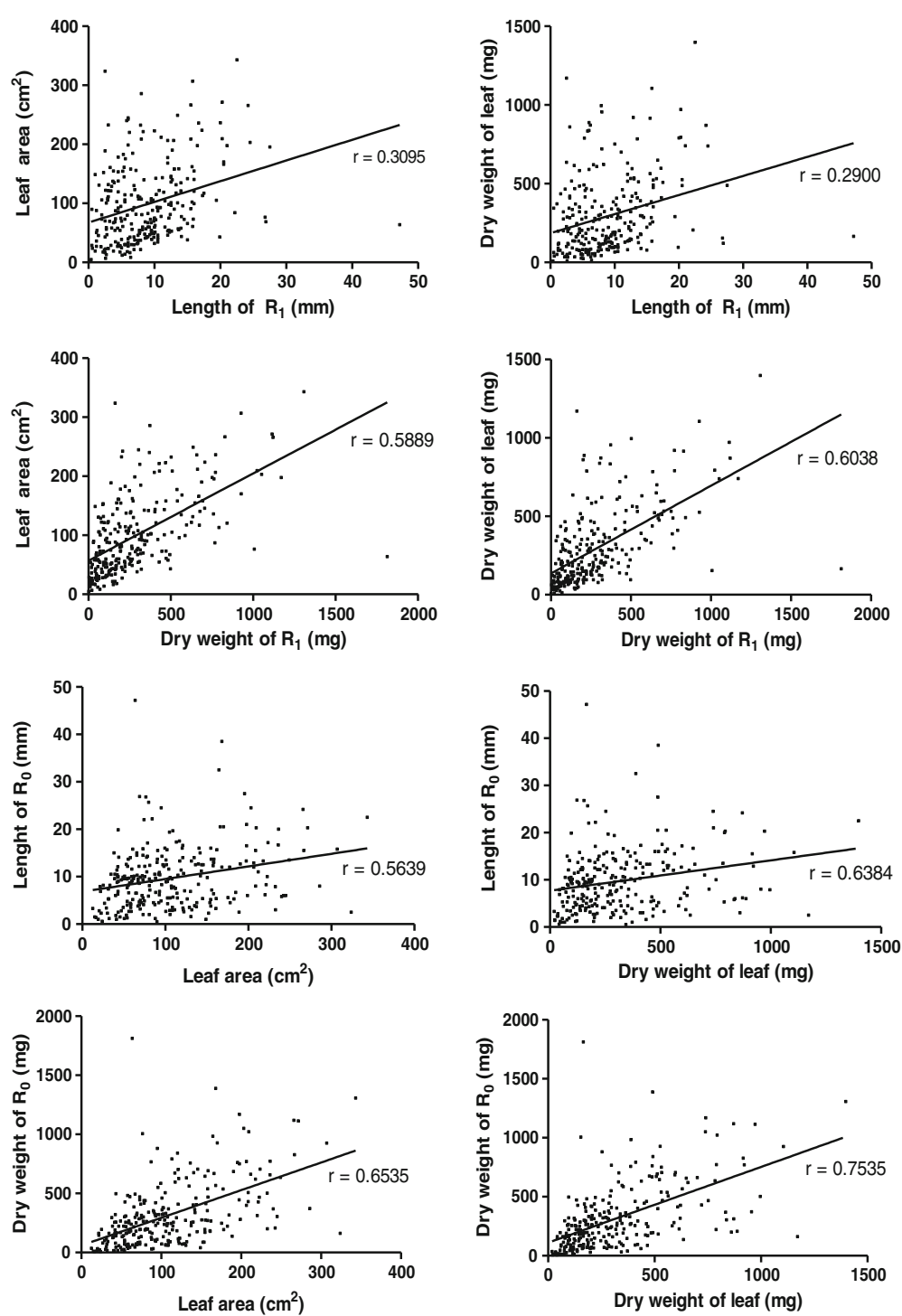

Fig. 6 Relationship between the rhizome property and the shoot one. $R_{0}$ and $R_{1}$ indicate the rhizome of this and last year, respectively

shoot sprouted. Moreover, rhizome dry weight decreased to $37 \%$ (from $758.8 \pm 211.1$ to $284.6 \pm 88.5 \mathrm{mg} \cdot$ plant $^{-1}$ ) after shoot sprouting. The total dry weight of a plant (root system + shoot system) was smaller than before shoot sprouting. This result indicates considerable energy expenditure for respiration during shoot sprouting. It may be impossible for the same rhizome to produce shoots twice because of insufficient energy. No shoots were found on $R_{2}$ (rhizome that developed 2 years ago) or $R_{3}$ (rhizome that developed 3 years ago) which attached to $\mathrm{R}_{1}$ (Hasegawa and Kudo 2005). Under optimal conditions, offspring production does not depend on the "starting capital" in the hibernacle; but under growth-limiting conditions, a thick hibernacle may be more successful in Helianthus x latifolius (Verburg et al. 1996). Third, the size of each plant organ increased with the number of leaves per plant and the difference corresponding to a one-leaf increment was significant at 1-5\% level. Thus, the number of leaves was a good indicator of plant size. Although rhizome size increased with the number of leaves, most differences were not significant; in particular, plants with a small number of leaves (3 to 7 leaves) showed no significant differences, likely because small plants could not fully receive sunlight like the larger plants. The reason for this inference was that small plants had low SLA values and, as a result, grew more slowly than large plants. As expected, plants with many leaves were taller than plants with fewer leaves. Thus, $P$. humile appears to sense and to respond to microclimate. Fifth, the $\mathrm{CC}$ values between rhizome and shoot sizes were significant at $1 \%$ level. In general, organic matter is transported from $R_{1}$ to the stem and leaves, whereas 

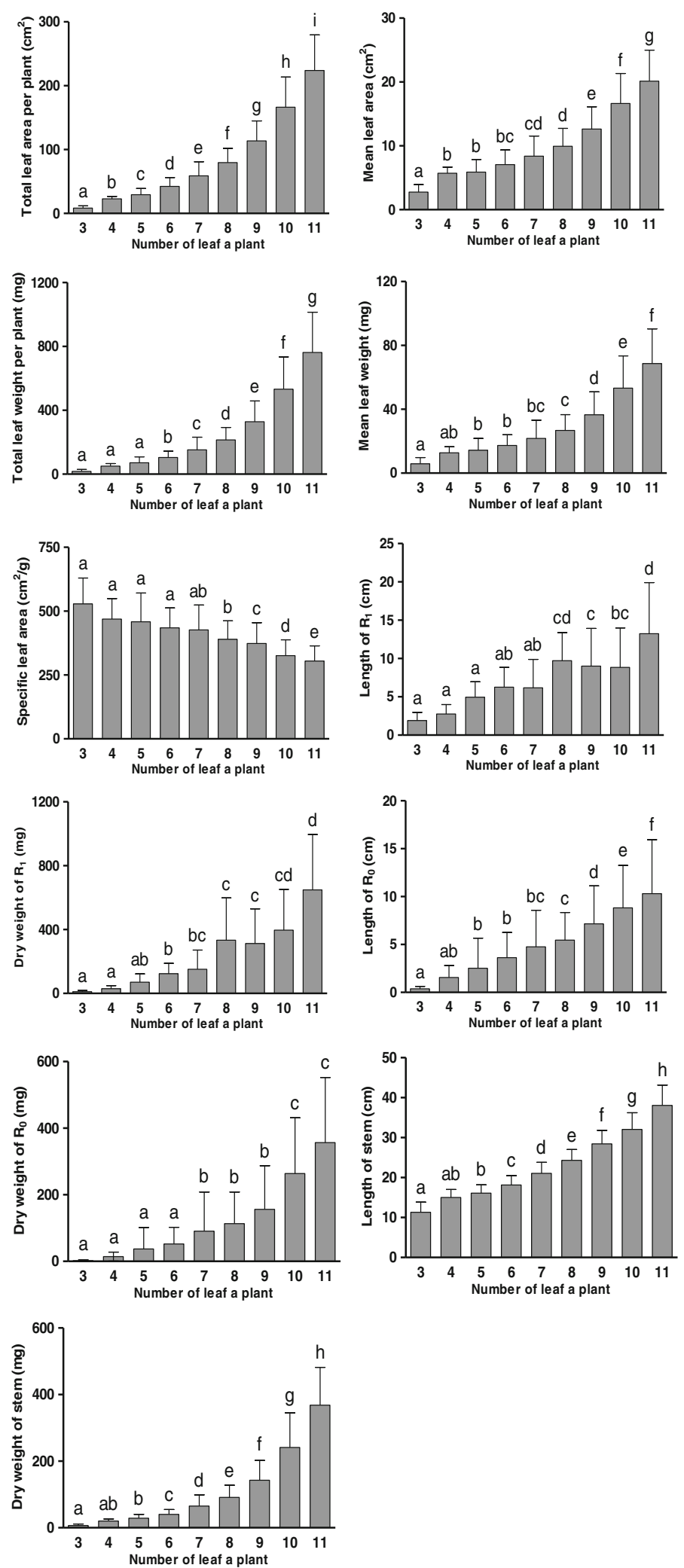

Fig. 7 Properties each organ along the number of leaves. Bar indicates standard deviation. Letters from " $a$ " to " $h$ " indicate that differences among the plants along the number of leaf are significant at $1 \%$ level 

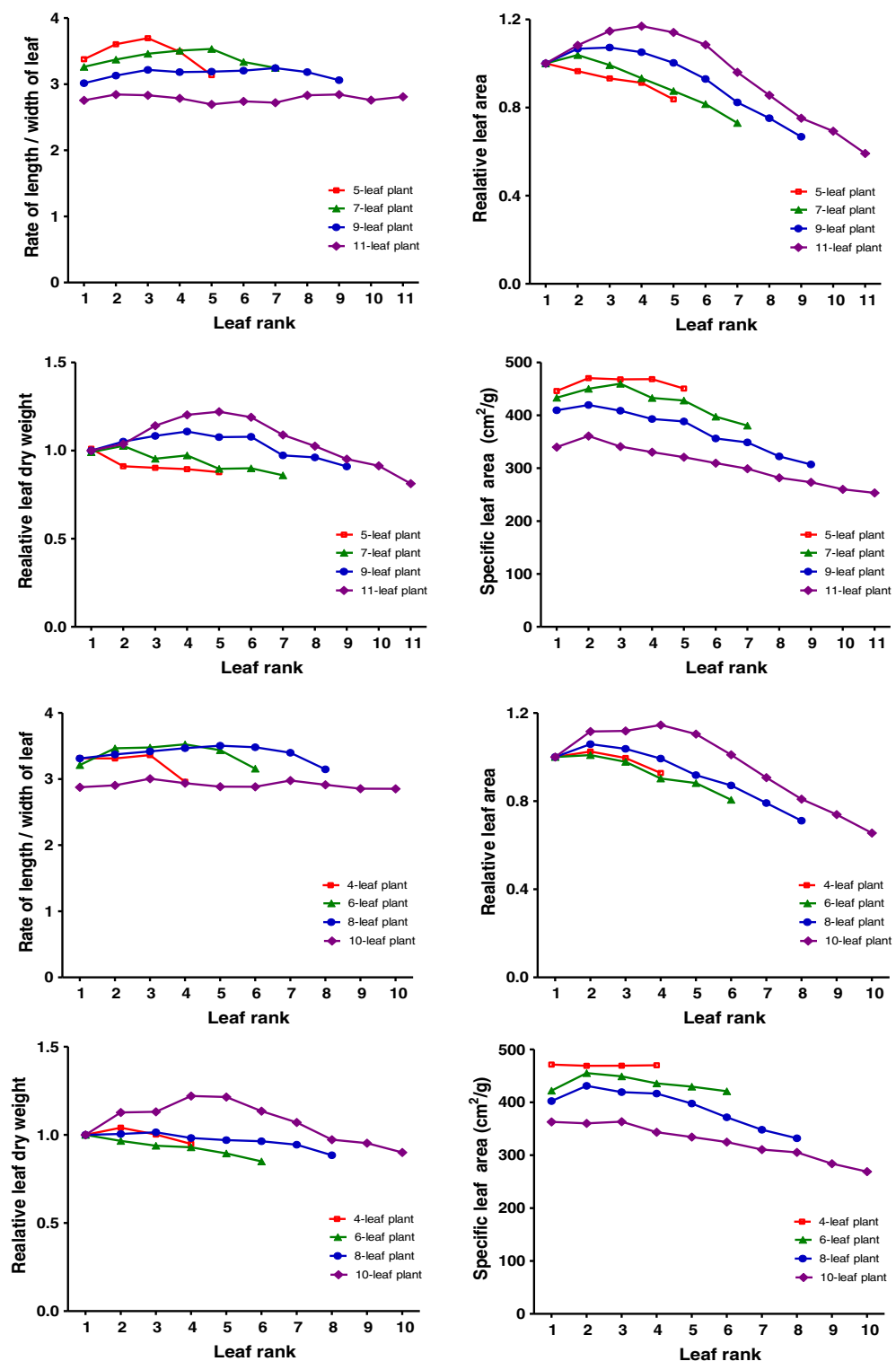

Fig. 8 Changes of leaf properties along leaf rank on a stem from 4-L plant to an 11-L plant

photosynthetates are transported from leaves to $R_{0}$. Thus, rhizome and shoot are closely related. In general, the leaf area is used to estimate of photosynthetic productivity, possibly because, in the field, the amount of sunlight received by each leaf affects leaf dry weight and direct sunlight induces leaf thickening and reduces the SLA (Ferreira et al. 2013). As mentioned above, SLA values were smaller in tall plants than in short plants because the former received more sunlight than the latter. SLA is a good indicator for recipient sunlight gradient (Dwyer et al. 2014) and leaf weight might change according to cumulative sunlight exposure. Finally, in plants with the same number of leaves, the values of four leaf properties first increased and then decreased along the leaf rank on a stem. However, the curves fluctuated slightly in plants with a small number of leaves. This fact indicates that the properties of leaves at the same node are diverse in small plants due to variation in the amount of received sunlight. In 11-L plant, leaf area, SLA, and dry weight increased from the $\mathrm{L}_{1}$ to $\mathrm{L}_{2}$ or $\mathrm{L}_{3}$ or $\mathrm{L}_{4}$ and, thereafter, decreased to $\mathrm{L}_{11}$. Differences of leaf properties between the 2 leaves on a stem were significant for most at $0.1-1 \%$ level. From the leaf with the maximum value, the higher the leaf position, the less the SLA and the area values were. Thus, changes in these properties could be an adaptation to variations in sunlight. I believe that $P$. humile population examined had a good strategy for adaptation by avoiding the shade (Hasegawa and Kudo 2005). Woody plant leaves in 
temperate deciduous forest show heteromorphism along the leaf rank on a new twig, although the time needed for the growth from the $\mathrm{L}_{1}$ to the last leaf is short and each leaf might grow under the same sunlight conditions (Min 1995). P. humile leaves on a stem almost grew at the same time, so microenvironment might similarly affect all leaves. Thus, plant leaf might show diverse morphology with leaf rank on a stem or a twig under similar microenvironments.

\section{Conclusions}

\section{Relationships between the root and the shoot's systems}

Root system's biomass decreased in accordance with shoot sprouting and this resulted from considerable energy expenditure for respiration during shoot sprouting. Moreover, the $\mathrm{CC}$ values between rhizome and shoot sizes were significant at $1 \%$ level. Thus, rhizome and shoot are closely related. The growth of $P$. humile rhizome was longer at this study site than in others. This strategy of clonal plants might be the means to avoid shade in a forest gap.

\section{Relationships between the number and the properties of leaves}

The size of each plant organ increased with the number of leaves per plant, and the difference corresponding to a one-leaf increment was significant at 1-5\% level. Thus, the number of leaves was a good indicator of the plant size. Although rhizome size increased with the number of leaves, most differences were not significant, likely because small plants could not fully receive sunlight like the larger plants. The reason for this inference was that small plants had low SLA values and, as a result, grew more slowly than large plants.

\section{Changes in four properties along the leaf rank on a stem and the number of leaves}

For 11-leaf plants, two types of changes in four leaf properties along the leaf rank on a stem from $\mathrm{L}_{1}$ to $\mathrm{L}_{11}$ were observed, one producing a regular curve and the other one an irregular curve. In the former case, the values first increased and then decreased along the leaf rank. There were relative leaf area, relative dry weight, and SLA in these properties. In the latter case, the value irregularly fluctuated along the leaf rank and was the leaf length/width ratio. Thus, changes in the leaf sizes showed a regular trend along the leaf rank on a stem. However, change of leaf morphology along the leaf rank on a stem was irregular.

\section{Abbreviations}

(3 12)-L: (3 12)-leaf plant; a.s.I.: Above sea level; CC: Correlation coefficient; $L_{(1 \sim 12)}$ : Leaf's ordinal number on a stem; $R_{0}$ : New (this year) rhizome; $R_{1}$ : The last year's rhizome; $R_{2}$ : 2 years ago rhizome; $R_{3}$ : 3 years ago rhizome; $S L A$ : Specific leaf area
Acknowledgements

Not applicable.

Funding

Not applicable.

Availability of data and materials

The datasets analyzed during the current study are directly available from the fields (a natural population of P. humile), as mentioned in "Methods" section.

Ethics approval and consent to participate

Not applicable.

Consent for publication

Not applicable.

Competing interests

The author declares that he has no competing interests.

\section{Publisher's Note}

Springer Nature remains neutral with regard to jurisdictional claims in published maps and institutional affiliations.

Received: 22 February 2017 Accepted: 2 August 2017

Published online: 04 September 2017

References

Choung, Y.-S. (1991). Growth characteristics and demography of Polygonatum involucratum and Polygonatum humile ramet population. Korean J Ecol, 14, 305-316.

Cook, R. E. (1983). Clonal plant population. American Scientist, 71, 244-253.

Dong, M., \& Alaten, B. (1999). Clonal plasticity in response to rhizome severing and heterogeneous resource supply in the rhizomatous grass Psammochloa villosa in an inner Mongolian dune, China. Plant Ecology, 141, 53-58.

Dwyer, J. M., Hobbs, R. J., \& Mayfield, M. M. (2014). Specific leaf area responses to environmental gradients through space and time. Ecology, 95, 399-410.

Emborg, J. (1998). Understorey light conditions and regeneration with respect to the structural dynamics of a near-natural temperature deciduous forest in Denmark. Forest Ecology and Management, 106, 83-95.

Ferreira, G. N., Prado Jr., J. A., Schiavini, I., \& Melo, C. (2013). Plastic responses in tree architecture and specific leaf area of Xylopia aromatica Annonacea: Adaptations to environments with different light intensities. Braz J Bot, 36, 279-283.

Gao, Y., Xing, F., Jin, Y., Nie, D., \& Wang, Y. (2012). Foraging responses of clonal plants to multi-patch environmental heterogeneity: Spatial preference and temporal reversibility. Plant and Soil, 359, 137-147.

Hasegawa, T., \& Kudo, G. (2005). Comparisons of growth schedule, reproductive property and allocation pattern among three rhizotomous Polygonatum species with reference to their habitat types. Plant Species Biology, 20, 23-32.

Ishioka, R., Muller, O., Hiura, T., \& Kudo, G. (2013). Responses of leafing phenology and photosynthesis to soil warming in forest-floor plants. Acta Oecologia, 51, 34-41.

Jang, C.-C. (2002). A taxonomic review of Korean Polygonatum (Ruscaceae). Korean Journal of Plant Taxonomy, 32, 417-447.

Jang, K. H., Park, J. M., Kang, J. H., \& Lee, S. T. (1998). Growth and flowering characteristics of Polygonatum spp. J Medicinal Crop Sci, 6, 142-148.

Kern, C. C., Montgomery, R. A., Reich, P. B., \& Strong, T. F. (2013). Canopy gap size influences niche portioning of the ground-layer plant community in a northern temperate forest. Journal of Plant Ecology, 6, 101-112.

Klinkhamer, P. G. L., de Jong, T. M., \& Meelis, E. (1990). How to test for proportionality in the reproductive effort of plants. Amer Natl, 135, 291-300.

Lee, T. B. (2003). Coloured flora of Korea (p. 676). Seoul: Hyangmoon.

Legner, N., Fleck, S., \& Leuschner, C. (2013). Low light acclimation in five temperate broad-leaved tree species of different successional status: The significance of a shade canopy. Annals of Forest Science, 70, 557-570.

Min, B. M. (1995). Growth and heteromorphism of leaves along the leaf rank (plastochron) of woody plants. J Plant Biol, 38, 63-72.

Seo, Y.-S., Park, W.-H., \& Cha, Y.Y.Y. (2011). Effect of Polygonatum odoratum on lowering lipid and antioxidation. J Oriental Rehab Med, 21, 49-62.

Verburg, R. W., Kwant, R., \& Werger, M. J. A. (1996). The effect of plant size on vegetative reproduction in a pseudo-annual. Vegetatio, 125, 185-192.

Whigham, D. F. (2004). Ecology of woodland herbs in temperate deciduous forests. Ann Rev Ecol Syst, 35, 583-621. 